\title{
'An evaluation of the Electronic Purchasing in Consortium database marketing at a New Zealand public library'
}

\author{
by
}

\section{Andrew Wreford Armour}

\author{
Submitted to the School of Information Management, \\ Victoria University of Wellington \\ in partial fulfilment of the requirements for the degree of \\ Master of Information Studies
}

\section{February 2014}




\section{Acknowledgements}

I would like to thank my supervisor Dr Philip Calvert for his guidance and patience, as well as Lynley Stone for inspiring the topic of this research. Great thanks also goes to my family and friends for supporting and encouraging me during the course of this research. 


\title{
VICTORIA UNIVERSITY OF WELLINGTON \\ School of Information Management \\ Master of Information Studies
}

IMPORTANT DISCLAIMER

with respect to a MIS Research Project (INFO 580)

\section{'An evaluation of the Electronic Purchasing in Consortium database marketing at a New Zealand public library'}

\section{(hereafter referred to as 'The MIS Research Project')}

\author{
being undertaken by
}

\section{Andrew Wreford Armour}

in partial fulfilment of the requirements of the degree of Master of Information Studies,

School of Information Management, Victoria University of Wellington.

\section{Topic Commencement: November 2012}

1. Victoria University of Wellington and its Council, its members, staff, employees, students and agents undertake no duty of care in contract, tort, or otherwise, to users (whether direct or indirect) of the MIS Research Project and make no warranties or representations of any kind whatsoever in relation to any of its contents.

2. The MIS Research Project is only made available on the basis that all users of it, whether direct or indirect, must take appropriate legal or other expert advice in relation to their own circumstances and must rely solely on their own judgement and such legal or other expert advice.

3. Under no circumstances will Victoria University of Wellington and its Council, its members, staff, employees, students or agents be liable in any way whatsoever, whether in contract, tort (including negligence), for breach of any statutory or regulatory duty (to the fullest extent permissible by law), or otherwise, to any user (whether direct or indirect) of the MIS Research Project for any loss or damage whatsoever arising directly or indirectly as a result of the use in any way of the MIS Research Project.

4. Each exclusion in the clauses of this disclaimer and each protection given by it is to be construed as a separate exclusion applying and surviving even if for any reason any of the exclusions or protections are held inapplicable in any circumstance. 


\section{Contents}

\section{Abstract}

\section{Keywords}

Introduction.

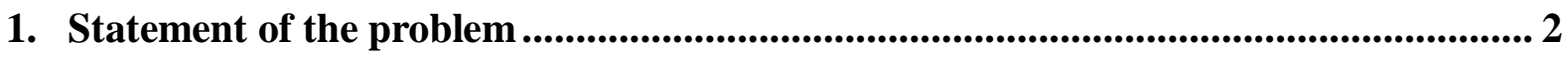

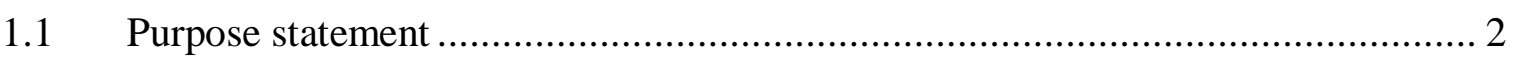

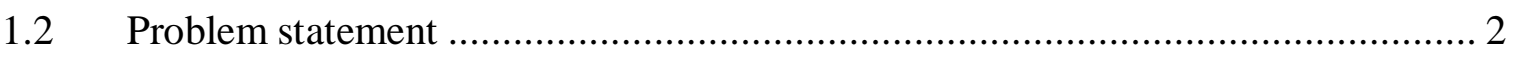

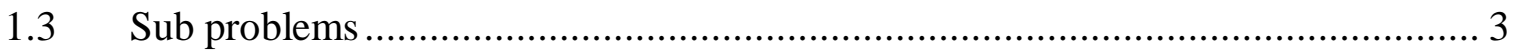

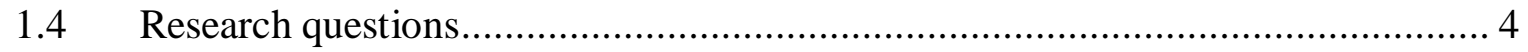

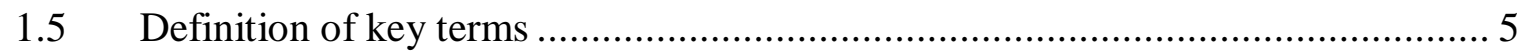

2. Literature review ............................................................................................................... 8

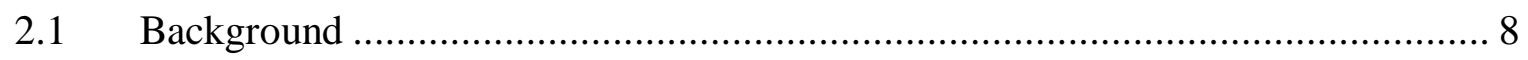

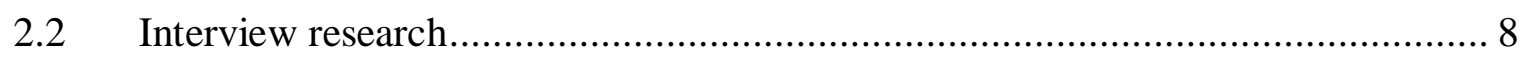

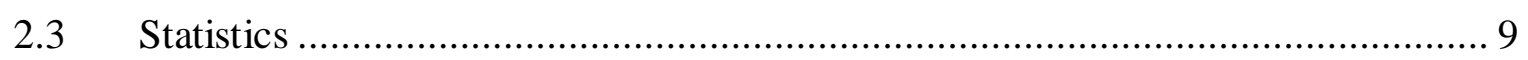

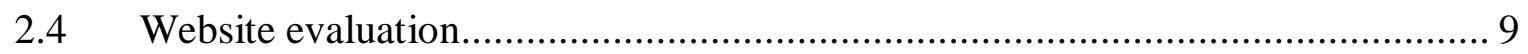

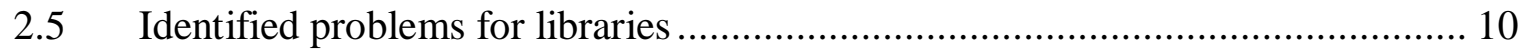

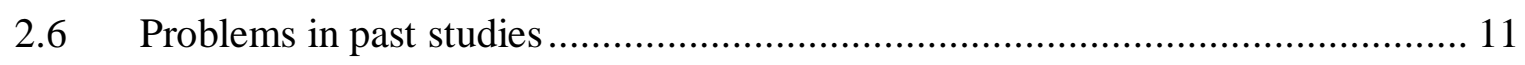

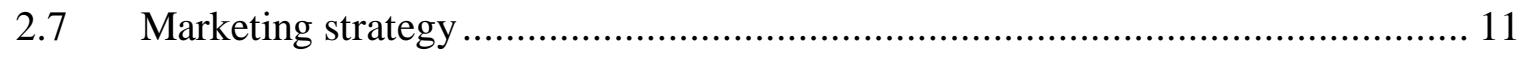

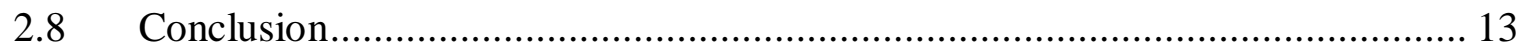

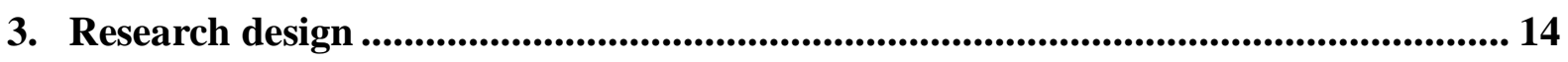

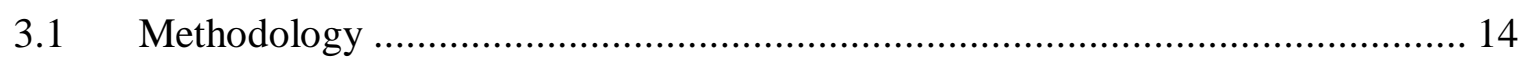

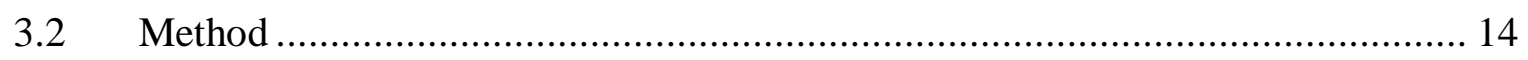

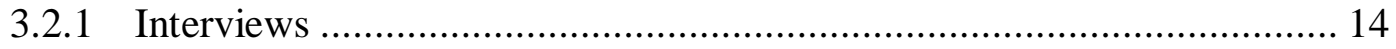

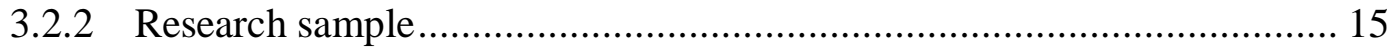

3.2.3 Limitations and delimitations ..................................................... 15

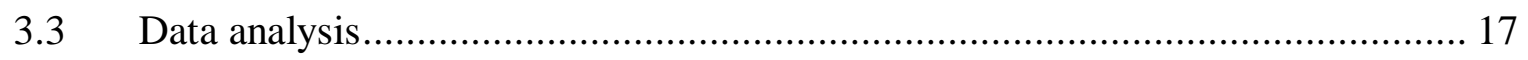

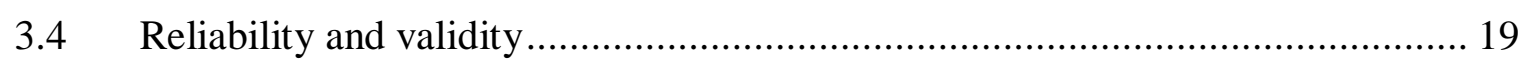

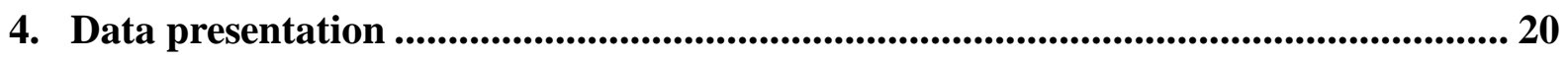

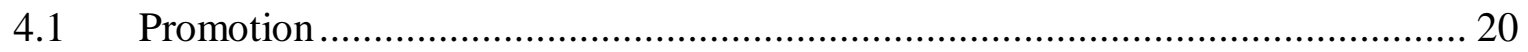

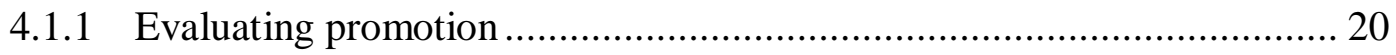

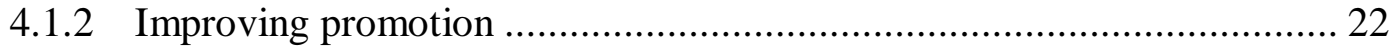

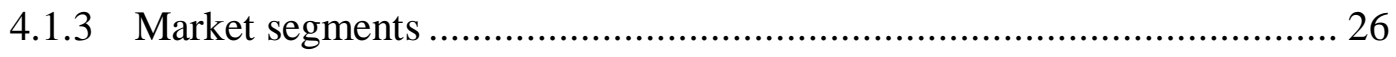

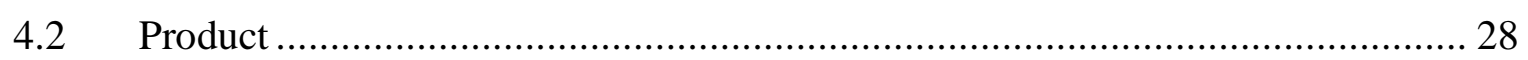

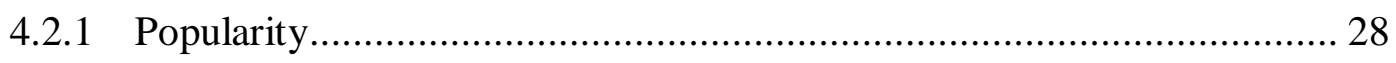

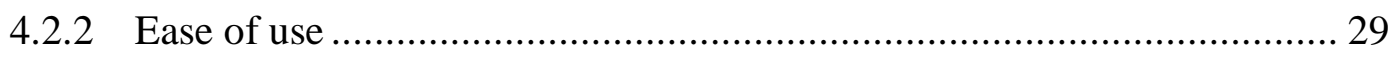


4.2.3 Priority of EPIC databases ............................................................. 30

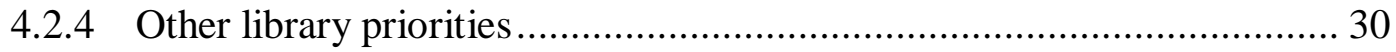

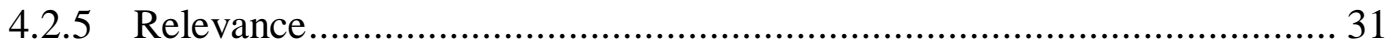

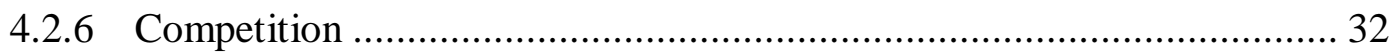

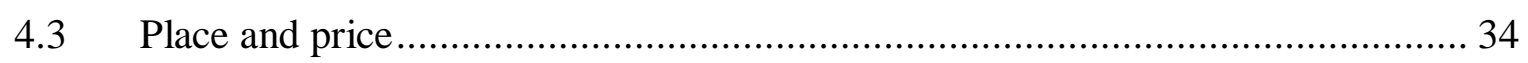

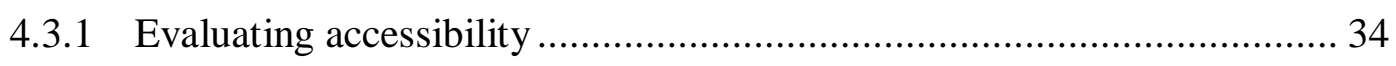

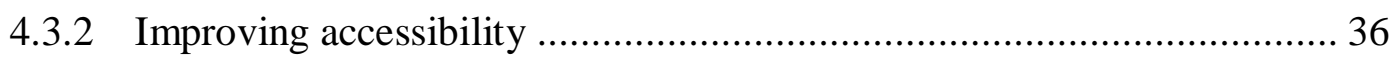

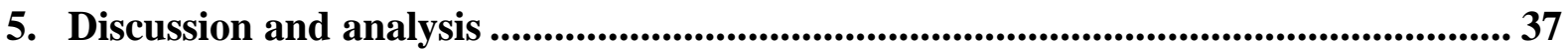

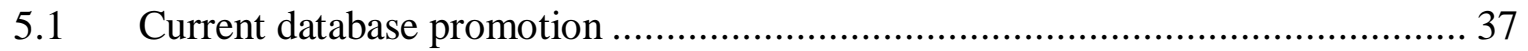

$5.2 \quad$ Market segments and product relevance ......................................................... 39

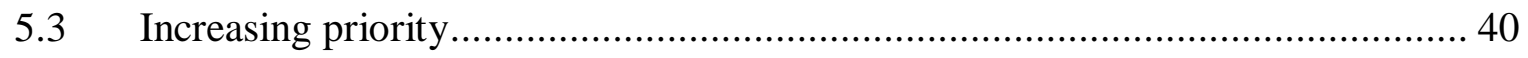

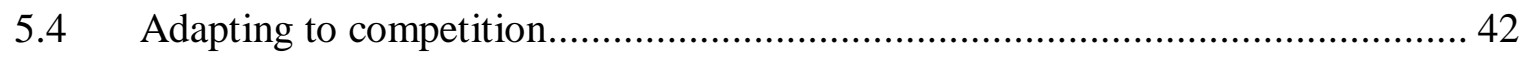

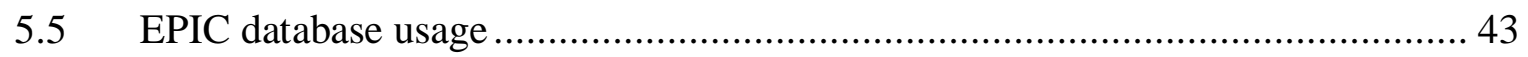

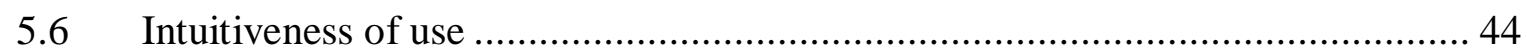

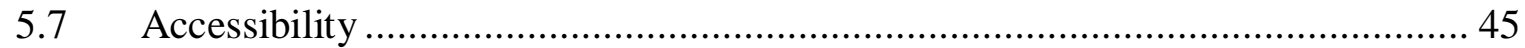

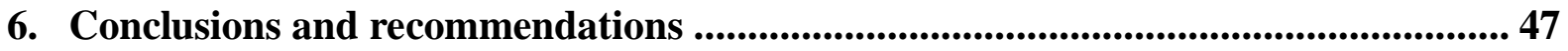

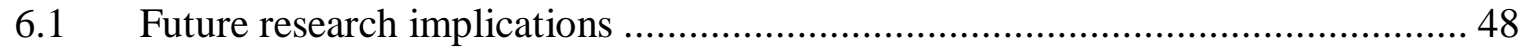

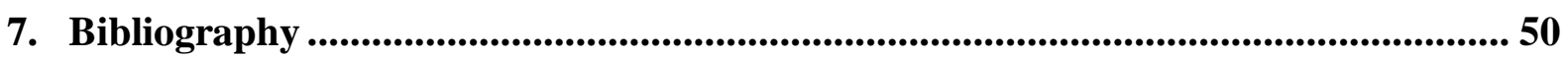

8. Appendices................................................................................................................................... 53

Appendix A: Library EPIC database subscription list ............................................. 53

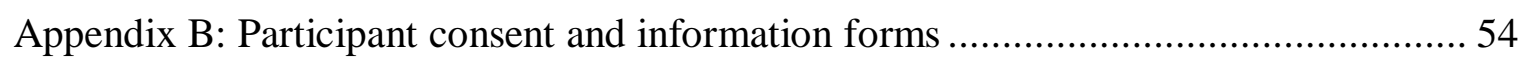

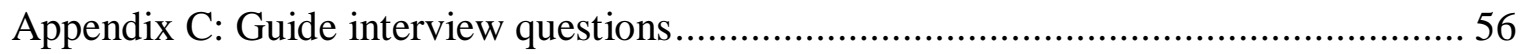




\begin{abstract}
Research problem

The Electronic Purchasing in Consortium (EPIC) databases are a useful paid resource that some librarians consider to be underused. Marketing is a key means of increasing awareness and use of library resources, but research into EPIC database marketing is sparse. This study investigated ways of improving the efficiency of marketing at a New Zealand public library through conversations with library staff and a customer.
\end{abstract}

\title{
Methodology
}

Data was collected through five semi-structured face-to-face interviews and was qualitatively analysed with reference to the product, price, place and promotion of a public library's EPIC databases.

\section{Results}

It was found that the library does not market its EPIC databases and that there is a connection between inadequate promotion, low customer awareness and low usage of the EPIC databases. EPIC database accessibility and staff training in database use were found to be areas in need of work. These issues were in part explained by the low priority the EPIC databases had at the library when compared with community outreach initiatives.

\section{Implications}

This study recommends market research be carried out, followed by targeted promotional efforts, further customer and staff training in the use of EPIC databases and more prominent web links to databases. It also recommends the library look into ways of using the EPIC databases in its customer outreach initiatives.

\section{Keywords}

- Public library

- Electronic Purchasing in Consortium (EPIC)

- Marketing

- Evaluation

- Qualitative research. 


\section{Introduction}

According to the Electronic Purchasing in Consortium's (EPIC) website, EPIC is “a consortium of libraries that license packages of electronic resources to be used in New Zealand libraries" which works together with libraries and resource vendors for mutual cost reduction; to help libraries access and use resources; and aids libraries in the promotion of their e-resources (2011, EPIC website: About Epic). EPIC gives access to a wide range of digital resource packages at cost to libraries. Over 150 New Zealand libraries from all sectors are EPIC members (2011, EPIC website: About Epic).

There has been little research in New Zealand concerning the EPIC databases and none seeking to aid EPIC marketing initiatives in public libraries. This study aimed to investigate how the marketing of the EPIC databases at a public library (which has asked to remain anonymous) in New Zealand could be made more efficient. It assessed marketing with reference to the product, price, place and promotion of the EPIC databases. This was done through interviews exploring customer and staff opinion of the promotion, marketing strategy, competition, priority, accessibility, usability, and relevance of the library's EPIC databases.

Beginning in April of 2014 EPIC's subscription model will change so that it “... will no longer offer the multi-vendor packages that member libraries have traditionally selected from. There will, however, be vendor specific package options and individual product offerings" (2013, EPIC website: EPIC News). This may mean that the EPIC databases are bumped up in priority while assessing new subscription models and provides an opportunity for fresh marketing initiatives. While this study focused on current EPIC subscription models and marketing efforts, the forthcoming changes to EPIC arose as topics of discussion. 


\section{Statement of the problem}

\subsection{Purpose statement}

This study aimed to gain an understanding of how library staff and customers felt about the marketing of their library's EPIC databases and to offer recommendations to improve marketing. Library staff and customer opinion was compared and contrasted to see if a disconnect existed between their feelings on marketing efforts and EPIC database customer relevance. As a by-product, awareness of the EPIC databases was raised among staff interviewees and useful marketing ideas were discussed. A replication of this research in other public or school libraries could also raise awareness of the EPIC databases so that, if marketing issues exist, a concerted effort among New Zealand libraries to strengthen marketing and increase usage might be prompted.

This study was undertaken using qualitative methods of evaluation. Data was gathered through interviews with library staff and a customer then organised under headings related to the research sub questions. It was then analysed to identify any consensus or disagreement and pinpoint areas for improved marketing initiatives.

Because this was a limited study of one public library with a small number of interviews, further research is necessary to understand to what extent inadequate marketing at this library negatively affects EPIC database use. Further research would also offer better means of improving the efficiency of EPIC databases marketing initiatives. No claims about other New Zealand public or school libraries can be made from this study. Research comparing two or more public libraries would prove beneficial to understanding what public library staff and customers think of the EPIC databases and how they are marketed throughout New Zealand. The forthcoming changes to EPIC subscription models mean that changes are inevitable. Because of this, a similar study in the future may elicit entirely difference results.

\subsection{Problem statement}

The need for this study stemmed from the potential value of the EPIC databases as a resource, their low usage, their cost to libraries and the un-investigated possible consequences of libraries dropping their subscriptions to EPIC. The EPIC databases add value in the form 
of knowledge to local library communities and businesses that use them. Cherrie and Rigby (2007, p.2) commented on the "comparative neglect of EPIC databases" suggesting inadequate staff training as one factor. Staff training was not a primary focus of this study, but it came up during staff interviews.

Tightening public library budgets enforce the need to justify the cost of maintaining access to electronic databases. The Public Libraries of New Zealand: A Strategic Framework (2012, p.34) established that demonstrating a return on investment is important to libraries. This study aimed to help improve a library's database marketing and increase usage for a better return on investment. It is possible, but un-researched, that low EPIC database usage could influence libraries to reduce spending on EPIC subscriptions. If libraries can no longer justify paying for their EPIC databases because they are underused, the libraries retaining subscriptions will shoulder an increased financial burden. This may have a negative effect on EPIC's service provision. Investigation into these consequences may be warranted in the future depending on the outcome of the new EPIC subscription methods in 2014.

\subsection{Sub problems}

This study focused on discovering:

- The effectiveness of the product, price, place and promotion of the EPIC databases, according to library customers and staff

- What priority the EPIC databases have at the library

- To what extent the product (EPIC) is of value to the library and its customers

- If poor promotion is a cause of low EPIC database usage

- What can be done to improve the promotion of EPIC databases

- If there is an identifiable and coherent marketing strategy that considers competition to the EPIC databases. 


\subsection{Research questions}

\section{Main research question:}

How can the selected public library market its Electronic Purchasing in Collaboration databases more effectively?

\section{Sub questions:}

- How does the library promote the EPIC databases? This will show what library staff and customers think about current EPIC database promotion. This knowledge might highlight areas of strength or areas of weakness for future improvement efforts.

- Does inadequate promotion negatively affect EPIC database usage? This aims to examine one possible cause of low EPIC database use. If shown to be the case, steps can be taken to improve promotion, based on answers to the next question.

- What can be done to improve promotion? This aims to gather ideas for promotion from users of the EPIC databases and library staff by encouraging interviewees to consider promotion and offer helpful ideas.

- How is the library targeting current EPIC promotion? This will show whether the library targets market segments when promoting the EPIC databases. This knowledge will form an important step towards assessing marketing effectiveness.

- What priority do the EPIC databases have at the library? This will gauge EPIC database priority compared to other library initiatives. It may shed light on the current EPIC database situation and give context to the first sub question: 'How well does the library promote the EPIC databases?'

- Are the EPIC databases relevant to library customer's needs? This may show if staff and customers agree on EPIC database relevance and aid future subscription decisions.

- Are the EPIC databases well used by library customers? This aims to see discover if a connection between promotion and EPIC database usage exists. Answers connecting the two may justify improving EPIC database marketing.

- What competition is there to the library's EPIC databases and what can be learned from this competition? This will show if library staff have thought about alternative sources of information their customers might use instead of the EPIC databases. It 
may also show how library customers compare the EPIC databases to resources like Google and Wikipedia. This knowledge may help libraries to think of appealing ways to market the EPIC databases.

- How accessible are the library's EPIC databases and can accessibility be improved? This will show if library staff and customers think the EPIC databases are accessible and hopes to uncover ways of improving database visibility and accessibility.

- Are the EPIC databases intuitive to use? This aims to discover if individual databases are discouraging use due because of navigational or operational difficulties. Answers may justify staff and customer EPIC database training.

\subsection{Definition of key terms}

\section{Accessibility}

How easily a staff member or customer can locate the EPIC databases through the library's website or catalogue.

\section{Competition}

Other sources of information that library staff or customers use for information needs that could be satisfied through the use of library's EPIC databases. These include Google, Wikipedia as well as University and school provided databases.

\section{Electronic Purchasing in Consortium (EPIC)}

EPIC is "a consortium of libraries that license packages of electronic resources to be used in New Zealand libraries" which works together with libraries and resource vendors for mutual cost reduction; to help libraries access and use resources; and aids libraries in the promotion of their e-resources (2011, EPIC website: About Epic).

\section{EPIC databases}

The 19 electronic resources that the study library subscribes to through EPIC. These databases are accessible through the library's catalogue and internet resources link. A list can be found in the appendices. 


\section{Internet resources}

Internet resources is a link on the study library's home page that leads to a list of subject headings under which the EPIC databases and other electronic resources are found. This is not the actual name of the link, it has been renamed to keep the study library's name confidential.

\section{Intuitiveness}

How easily a staff member or customer can navigate and retrieve results using the EPIC databases without aid.

\section{Kōtui}

"Kōtui is a shared library management and resource discovery service available to New Zealand public libraries on subscription" (n.d., Kōtui website: About Kōtui). At the study library, Kōtui is the current library management system and discovery service.

\section{Library discovery service (LDS)}

"A single interface, providing integrated access to the multiple information resources (catalogs, publishers' e-book and e-journal collections, subscription databases, archival collections) to which a library has rights. Discovery systems use consolidated subject indexing and metadata.” (2014, Reitz: discovery service).

\section{Library management system (LMS)}

A LMS is “... an integrated set of applications designed to perform the business and technical functions of a library, including acquisitions, cataloging, circulation, and the provision of public access" (2014, Reitz: library management system).

\section{Market segmentation}

As stated by de Saez (2002, p.115) "...segmentation is the division of the library or information centre's market into smaller, more manageable, groups that have like characteristics."

\section{Online Public Access Catalogue (OPAC)}

"...a database composed of bibliographic records describing the books and other materials owned by a library or library system, accessible via public terminals or workstations usually 
concentrated near the reference desk to make it easy for users to request the assistance of a trained reference librarian.” (2014, Reitz: OPAC).

\section{Relevance}

How interviewees feel the EPIC databases meet with their resource needs.

\section{Social networking sites}

Social networking sites are online tools that the library uses to converse with customers, promote events and advertise resources. The library uses Twitter, Facebook, Flickr, Vimeo and YouTube.

\section{The four Ps of marketing: product, price, place and promotion}

According to Dubicki (2007, pp.6-7), the four Ps are usually used by for-profit businesses, but are adaptable to a non-profit library situation. Applied to this research:

- The product is the library's EPIC databases

- The price refers to time spent accessing resources and the cost to the library for being part of the consortium

- The place is the library's website or catalogue, through which a customer accesses the product

- Promotion refers to the electronic, physical or word of mouth advertising of the EPIC databases. 


\section{Literature review}

\subsection{Background}

A review of the related literature uncovered no research specific to EPIC database usage. The reviewed literature dealt with research carried out through interviews, statistical research, website evaluation, identified marketing problems for libraries, problems in past studies, and marketing strategy.

Most research came from overseas and concerned marketing in academic libraries, with a smaller amount of research conducted in public, school and special libraries. As academic libraries have a strong focus on material for high level research, solutions for academic libraries may not be suitable for public libraries with more diverse user bases and less academic needs.

The information on website analysis did not prove useful to this study because a website analysis was not carried out due to time constraints.

\subsection{Interview research}

Two studies that were reviewed utilised interviews as their methods of data collection. Vasileiou's (2011) goal was to understand how promotion and marketing of electronic books was done in academic libraries and was achieved by collecting qualitative data through semistructured staff interviews at academic libraries. However, nineteen out of twenty-five staff interviewed were subject librarians. Vasileiou did not try to establish how well non-library academic staff thought they were marketing and no student opinion was sought for a better evaluation of performance. In addition to this, six out of seven libraries that Vasileiou examined had less than 115,000 e-books and four libraries with fewer than 25,000. These smaller collections might have suggested libraries with fewer resources to be devoted to marketing and could represent a bias in the study. Vasileiou's study aided the researcher's understanding of how a qualitative study could use staff interview data to evaluate marketing of electronic resources in libraries. 
Kavulya (2004) performed a qualitative case study through interviews at selected university libraries in Kenya and examined their methods of marketing library services. Kavulya (2004, p.118) stressed the position that “...marketing involves finding out what the users want, then setting out to meet those needs..." This opinion influenced the researcher's decision to interview rather than focus on usage statistics or a website analysis for this study.

\subsection{Statistics}

A different study obtained user and usage statistics for data. McClure, Mandel \& Weissenberger (2012), looked at the creation of a user and usage database that would analyse the users and their use of the Florida Electronic Library, a state-wide, licensed database. They identified what databases were least used and in which counties, to target these for improvements. McClure et al.'s end goal was to create focused marketing campaigns for the general population. Their goal was similar to this study's, however, it analysed usage statistics rather than interviews. McClure et al. (2012, p.369) looked at usage per capita by measuring “...full-text, retrievals, searches, and sessions.” McClure et al.'s research highlighted the possibility of analysing usage statistics, but a qualitative rather than quantitative research had already been decided upon by the researcher.

\subsection{Website evaluation}

Brower (2004) evaluated forty-one Academic health sciences library (HSL) websites and their navigation tools, including electronic resources. Brower saw that HSL user base shared similar traits and thought homogenising HSL websites would be beneficial. Brower's study duplicated websites for later examination without fear of changes (2004, p.414). This could aid similar research dealing with multiple public library websites. Brower also made a distinction between direct links and roundabout links (2004, p.414). This could be used to evaluate the accessibility of other electronic resources.

Brower talked extensively about persistent navigation tools (PNT) that appear on all pages of a website and link to "...the primary information and service areas of the site" (2004, p.413). A PNT for the EPIC databases might increase customer awareness and usage. Brower also stated that the collected data "...suggest that academic HSLs anticipate that their user bases 
are already familiar with specific databases..." (2004, p.418). Do the staff members at the study library make the same mistake?

Kaba examined the marketing of information resources on the internet at academic libraries in the United Arab Emirates, hoping “...to provide recommendations to libraries for the improvement of their marketing strategies on the web" (2011, p.59). To achieve this, Kaba asked "What can be done to improve the usability of websites for marketing library resources and services?" (2011, p.60). Kaba's answer considered visibility, general information, consultation, online services, online resources and networking on library websites (2011, p.60). Kaba mentioned “...mouse-over, pop-up and pull down links” (2011, p.60) as indirect points of access, but did not explore any possible negative effect these had on use.

These resources helped shape early consideration of a website analysis in this study, but focus was given solely to a qualitative analysis of interview data.

\subsection{Identified problems for libraries}

The literature review identified problems encountered by past marketing analysis studies. Hart, Coleman \& Yu (2000) assessed use and awareness of electronic resources by faculty and teaching staff at Texas A\&M University. Hart, et al. (2000, p.45 \& 47) saw that a lack of information, time and training for staff in the use of electronic resources were causing low use. This influenced a staff interview question designed to evaluate proficiency with the EPIC databases. Hart, et al.'s solutions included better physical marketing, improved customer communication and more electronic resources usage training; all adoptable recommendations for this study.

Kaur (2009) described the marketing initiatives that twenty-two Malaysian academic libraries used to promote their collections and services through their websites. Kaur believed that librarians were not in touch with user needs and that consequent poor marketing of library resources meant users had no reason to stop relying on internet search engines for information. These two points were key to formulating this study's research questions on EPIC database relevance, marketing and competition. 
Schmidt (2007) investigated changes in the information environment and recommended methods of marketing library services. Schmidt dealt with libraries broadly and consequently recommendations were general. However, this generality complements the other research focusing on academic libraries. Like Kaur, Schmidt highlighted the importance of communication and knowledge of customer needs to market effectively. Schmidt identified marketing techniques inspired by for-profit organisations, including product development, badging and promotion strategies (2007, p.341-342). These are all suitable suggestions for libraries and were considered as recommendations for the library in this study.

Kavulya (2004, p.122) outlined three problems for library marketing, including declining budgets, growing competition from internet sources and advances in information technology. These are very similar to the problems facing public libraries in New Zealand.

\subsection{Problems in past studies}

A problem in Kaur's data collection was that only nine library managers were interviewed and as such they did not contribute significantly to the study. User interviews could have established the success of marketing initiatives. This reinforced the need to recruit both staff and customers for this study.

Kennedy (2011) aimed to discover electronic resource marketing techniques used by libraries and how these libraries assessed marketing effectiveness. Kennedy implied that libraries struggled to develop modern ways of electronically marketing growing online resource collections to replace dated physical marketing. The problem with Kennedy's findings is that they were based solely on an interpretation of literature. Clarification through human interaction might have made the study more accurate. Identifying this confirmed the need to speak with staff to answer the research questions.

\subsection{Marketing strategy}

Like Kennedy, Vasileiou (2011) stressed the importance of a strategic marketing plan. Vasileiou's (2011, p.639) study libraries were found to lack marketing plans, which are integral to efficient services. Vasileiou's finding helped formulate this study's question on targeting market segments. 
Brannon's (2007) paper told how Denton Public library noticed low use of its electronic resources and began a marketing campaign coupled with improving staff expertise in electronic resource use. Increasing staff expertise hoped to improve customer usage. It is important to know that staff knowledge may have an impact on database usage. Physical and electronic marketing are both important for reaching the largest possible audience. Magnets, personalised pens, promotions in monthly newspapers and signage were used to spread the word about the electronic resources.

A recent marketing campaign for a virtual reference service was carried out at Texas A\&M University by MacDonald, vanDuinkerken and Stephens (2008). MacDonald et al. filled a literature gap by reporting on a marketing campaigns success. They uncovered similar issues, such as staff training and marketing (2008, p.376). Identifying a target audience to market towards was shown to be important. MacDonald et al. (2008) used different marketing techniques for freshmen, distance students and commuting students. Similar targeting could be performed for different age levels, cultures and interest groups at the public library considered in this study.

Ashcroft (2002, p.149) highlighted changing user expectations and the importance of accessibility and convenience in an examination of e-journal promotion in academic libraries in the United Kingdom (UK) and North America (NA). Ashcroft (2002, p.150) contributed valuable reasons for promoting, such as “...establishing communication, raising awareness of what is on offer, providing guidance and...providing user education" all of which were seen as important by staff in this study. Ashcroft's study concerned academic libraries from NA and the UK and for these marketing initiatives to work people must visit your website.

Ashcroft (2002, p.150) covered beneficial marketing collaborations between libraries and journal suppliers. Currently, EPIC offers advice on marketing, how to attract users and usage training through its website. It might be worth examining how effective these initiatives are in future studies, especially given the upcoming changes to database subscription.

Kavulya's research showed that while Kenyan libraries advertised their resources well they lacked formal marketing research strategies and statistics on expenditure, collection growth 
and lending (2004, p.124). The above research clearly justifies the need for libraries to have a marketing strategy to effectively reach their customer base.

\subsection{Conclusion}

The importance of the EPIC databases necessitates a deeper look into their marketing and use throughout New Zealand libraries. This is especially clear given the information gap in this area. This study seeks to act as a starting point through evaluating one public library's EPIC database marketing. 


\section{Research design}

\subsection{Methodology}

This study took a qualitative approach consisting of a one off case study of a New Zealand public library. Semi-structured face-to-face interviews were performed to gather data to solve the research problems and answer the research questions. As outlined by Patton (2003, para.2) "Qualitative evaluations emphasize reporting program participant's experiences in their own words." This approach was taken because it allowed interviewees to freely express their feelings about the library's EPIC database marketing. As Leedy and Ormrod (2013, p.141) pointed out "A case study may be especially suitable for learning more about a little known or poorly understood situation." As shown in the literature review, marketing of EPIC databases in New Zealand has not been well researched.

Peshkin (1993, p.24) listed description, interpretation, verification and evaluation as the four types of outcomes from qualitative research. Following this, the study aimed to:

- Describe current marketing situations

- Interpret any marketing problems

- Verify if inadequate promotion contributes to low EPIC database usage

- Evaluate the effectiveness of EPIC database promotion and marketing strategy.

This research is intended to be replicable in other public libraries.

\subsection{Method}

\subsubsection{Interviews}

The data in this study came from recorded semi-structured face-to-face interviews conducted with library staff and a customer. Semi-structured interviews were suitable because as Leedy et al. (2013, p.154) point out they are flexible and can elicit unexpected opinions. Guidance for the interviews were drawn from Rowley (2012, p.262), who explained that interviewing can be effective when "The research objectives centre on understanding experiences, opinions, attitudes, values and processes.” Rowley (2012, p.261) contrasted questionnaires 
with interviews as a method of data gathering, stating the former as likely to receive more responses, but the latter could provide useful insights and understandings. This study sought in depth answers and so interviews were chosen to allow for clarification and follow-up questions to increase comprehension.

\subsubsection{Research sample}

This study focused on one public library in New Zealand. Four library staff members from middle to upper management positions were interviewed in mid-December and one library customer was interviewed during January. These interviews ranged from 17 to 30 minutes in length.

Staff were interviewed for their perceived knowledge of marketing efforts and ability to formulate ideas to improve EPIC database marketing. Following Leedy et al. (2013, p.152), the sample aimed to include typical and non-typical examples, different levels of library staff hierarchy and cases that might "...discredit emerging hypotheses and theories.” However, this was not fully achievable.

\subsubsection{Limitations and delimitations}

\section{Research focus}

To limit the scope of this study, a number of areas related to the EPIC databases and their marketing were not explored, including:

- Customer computer literacy and its relation to EPIC database usage

- Customer home internet access and its effect on EPIC database use

- How non-users of the library regard the EPIC databases and ways of targeted marketing towards non-users

- A website evaluation considering accessibility, descriptions of EPIC databases and a judgement on how the library used the marketing resources provided on EPICs website

- The un-investigated and hypothetical consequences of multiple New Zealand libraries dropping their subscriptions to EPIC because of an inability to justify their expense 
- A detailed look at EPIC database usage statistics to quantify usage and suggest measurable future goals.

\section{Sample}

This study's sample was made up of one public library; studying two or more libraries would have provided more generalizable data. Because of the diversity in public library customers, a large sample size was desired so that data accurately represented the subject library. This would also have improved the generalisability of findings. To achieve a representative sample, customers of varying ages and ethnicities were to be approached as were a range of staff from different levels of the library hierarchy. In reality the researcher took the opportunities that were presented. Recruiting customers who used the EPIC databases and were interested in being interviewed was difficult, even with help from the library. The limited customer data has affected the ability of this study to draw solid conclusions on customer opinion of the product, price, place and promotion of the EPIC databases. Conversely, the wealth of data from library staff presented good information to evaluate EPIC database marketing and make recommendations.

A disadvantage of the chosen method of interviewing is that extensive users of the library website who do not often visit the library may have been missed. A further limitation was that library assistants who are in close contact with customers were not interviewed. Library assistants may have had a different understanding of the EPIC database situation.

\section{Bias}

Leedy et al. (2013, p.153) pointed out unreliability during interviews and that "People are apt to recall what might or should have happened (based on their attitudes or beliefs) rather than what actually did happen.” The following facts may have caused some bias:

- The researcher had worked at another library subscribed to EPIC and this influenced his opinion that the EPIC databases are a valuable resource

- The researcher had not used the EPIC databases for several years and was quite unfamiliar with them 
- The researcher had worked with two staff interviewees and this may have had unforeseen consequences during data collection.

However, the researcher had not frequented the study library and had no prior knowledge about its situation regarding EPIC or management. This should have helped him remain objective.

\section{Ethics}

Permission was sought from the participating library and received from library management in an email. The library asked to remain unnamed, therefore the website has not been named in this research. A link on the library's website that is referred to has been renamed 'internet resources' to make the study library less identifiable. The names of staff and customer interviewees are confidential and data is attributed to an alias so that individuals are unidentifiable. An explanation of the research goals and handling of data was provided in consent forms and information sheets that all interviewees read and signed. These can be found in appendix B.

Interview audio and notes were stored in a password protected and encrypted volume. Backups of these files were stored in a USB drive and protected in the same way. The software used to achieve this is called Truecrypt. The research data will be destroyed two years after the completion of the research.

Staff interviewees were recruited through a staff contact and confirmed by email. The customer was recruited by another staff member who had offered to help. A request for interested customers was put out by the library, but saw no response.

\subsection{Data analysis}

Data was presented and analysed using the following methods adapted from Leedy et al.'s (2013, p.141-142) data analysis steps. 
Presentation:

- Each interviewee's responses were colour coded so that they could be easily recognised from each other during data presentation. All quoted interview replies have been prefaced with a label, for example 'staff interviewee one' or 'customer one.' This follows Hart et al.'s study (2000) which made it clear that coding interview responses is important for a good interpretation of comments.

- The data was organised and presented under the main headings of Promotion, Product, Place and Price

- The research sub questions were placed under the relevant main headings

- Data was then gathered under the related sub questions

- Within the sub questions the data was organised by positive or negative responses, suggestions for improvement, problems and other categories of answers.

Analysis:

- The analysis was organised and discussed under the headings:

- Current database promotion

- Market segments and product relevance

- Increasing priority

- Adapting to competition

- EPIC database usage

- Intuitiveness of use

- Accessibility

- Patterns and repeating themes were sought in the data and synthesised to create a picture of the study

- Data from interviewees was compared and contrasted to find contradictions, suggestions and unexpected problems

- Staff and customer opinion was analysed to highlight gaps and discrepancies

- Attention was given to how staff answered the questions regarding market segmentation. Following de Saez (2002, p.116), to be successful the market segment must be homogeneous, accessible and measurable. These qualities influenced how to measure market segmenting success

- One of Flower's (2004, p.69) questions that aims to elucidate how well an organisation's databases are being marketed, namely "What competitive forces are 
acting on your library?" was modified; Customers and staff were asked what competition they thought the EPIC databases had. Answers to this question were examined to find out if anything could be adopted from competing resources to improve the visibility and accessibility of the EPIC databases

- Responses that did not fit into categories were studied carefully to understand what they meant to the study

- Conclusions were drawn from the data that established recommendations for improving EPIC database marketing through modifications or changes to the promotion, product, place and price.

\subsection{Reliability and validity}

To ensure reliability and validity of data and the study's results, the researcher followed Leedy et al. (2013, p162):

- Identified biases that could have influenced gathering and analysis of data

- Made an effort to perform the study objectively and be open to new conclusions

- Tried to come to conclusions and make recommendations that would prove viable and beneficial to the study library.

The research also:

- Asked follow up questions during interviews to ensure understanding

- Listened to interview recordings multiple times while taking notes and while writing the analysis

- Re-listened and transcribed quotes that helped to answer research questions. 


\section{Data presentation}

Data was gathered during five interviews with library staff and one customer to answer the over-arching research question:

How can the selected public library market its Electronic Purchasing in Collaboration databases more effectively?

Data is organised under the headings of Promotion, Product, Price and Place. Under these headings the relevant research sub-questions (in italics) further delineate the data.

\subsection{Promotion}

\subsubsection{Evaluating promotion}

How are the EPIC databases promoted?

All staff interviewees remarked that the library's EPIC databases are not being promoted and this was supported by the customer's opinion.

Staff interviewee one: "We have promoted them in the past in that we have had displays to promote one specific database just to raise awareness. But I have to admit that we haven't actually marketed them or promoted them in any way for quite some time."

Staff interviewee one: "A few months back we went with a discovery layer on our library management system, so at that stage I guess we perhaps didn't feel quite the need to promote them like we had before because when people are searching they're going to stumble across database results anyway."

Staff interviewee two: "We're not promoting that we subscribe to EPIC databases in any way shape or form...we're not promoting it, we're not valuing 
it, I feel. We're not giving it credit and we're not educating the public that it's there and how to be using them."

Staff interviewee three: "No, we used to have some big posters and this was a few years ago, advertising some of the databases, but I can't remember if they were EPIC or otherwise. But apart from that, no we don't at all."

Staff interviewee four: "They aren't really promoted at all."

Customer one: "There could be a bit more publicity...Not many people are aware of it I believe... The general public is not very familiar with it (EPIC) to be honest."

Two staff interviewees talked about customers being surprised at the existence of the EPIC databases.

Staff interviewee three: “...parents have even been astounded that we have that kind of resource (EPIC) available."

Staff interviewee four: "Because when customers come in... and they wanna find some specific information. And you say 'Well, this probably isn't gonna be in a book, but we could look in our databases' they kind of look at you blankly."

Three staff interviewees elaborated on past physical and electronic efforts to promote the EPIC databases.

Staff interviewee one: "We actually were doing physical promotion out in the library."

Staff interviewee two: "Once a month in our library news, which is a little newsletter that we produce every month that's available online and in hardcopy, we would feature a database from our (internet resources)... What it is and how you actually get to it... that's totally dropped by the wayside." 
Staff interviewee four: "A while back we used to have on our website an (internet resource) of the month kind of thing. And that used to also have some stuff out in the library for it. But that has fallen off in the restructure."

One staff interviewee saw EPIC database promotion as having a higher priority in the past because of how the old library discovery system worked.

Staff interviewee one: “... before when people had to actively go and look for a specific database to search on. So it was a lot more work without the discovery layer. And so I feel that promotion was probably more important."

This did not mean that promotion was un-important now.

Staff interviewee one: “...we have talked recently about maybe we should be promoting them more again now. Just so that students especially, but all library users know that we do have quite a few databases they can use. It is an area that we could do better in."

Staff interviewee four: "Having talked to you... it's reminded me how much we need to be promoting them (EPIC databases)."

\subsubsection{Improving promotion}

Is there anything you would like to see done to improve database promotion?

Two staff interviewees and the customer discussed promotion through community engagement.

Staff interviewee one: "(Important to make sure customers are)... aware of the fact that if they're searching from a research point of view that they can search more than just books... That would be what you would want to promote rather than individual databases.” 
Staff interviewee two: "We've got televisions in this place that sit doing nothing all day long. We could have that (information about EPIC) on a loop."

The customer desired training for EPIC database usage.

Customer one: "A bit more advertisement in the library magazine or noticeboard. Or even periodic advertisement of courses for the public... to teach them how to use them."

Staff interviewee two wished for a renewal of the EPIC databases section in the library's monthly newsletter (mentioned above).

Three staff interviewees saw staff as a vital way of educating customers about the EPIC databases.

Staff interviewee two: "At point of registration with a customer I actually take them through it (EPIC)... That is the one tab (internet resources) that I'll show them what's available in there. $99 \%$ of the time they're going 'Wow, that's amazing.",

Staff interviewee three: "I know that it (the EPIC databases) is accurate information. And that's something we try and pass on to people that we are doing reference queries for. Because in the day and age of Dr. Google they'll (customers) just look up anything. So it's sort of trying to explain the purity of that information versus what they'll find on any old site."

Staff interviewee four: "I know one on one with the customer can go a long way (during reference inquiries)."

Staff interviewee two argued that introducing newly registered customers to EPIC should be made common practice at the library. They said training schemes in 2014 to increase staff familiarity with the library's website content was planned to encourage database use over Google as a first step. This was because they believed staff familiarity could be better in this area. 
Staff interviewee two: “They're (staff) working with it all day, but they're not aware of everything that's in there (the library website)."

One interviewee had seen that some staff were not comfortable helping customers one on one with difficult queries.

Staff interviewee four: "No... any time a complicated question came up the other staff would say go see (staff interviewee four)."

Electronic promotion was seen by two interviewees as an important way of reaching customers:

Staff interviewee one: "The problem is: how do you promote it (EPIC databases)? We're really limited with actual physical space...But if you're talking about doing it on your website then that's probably where we should be looking."

Staff interviewee two: "I would like to see something that said EPIC databases right on the front page of our catalogue, right on the front page of our website."

Staff interviewee three: "I would like to see even on our homepage, directions to that (EPIC)."

Importantly, two staff interviewees suggested a New Zealand wide initiative aiming to promote EPIC databases.

Staff interviewee two: "Is there someone out there, is there a governing body, is it National library is it LIANZA, I don't know, is it just ordinary every day librarians that should be talking EPIC databases and get excited about it, sex it up a bit so that punters don't glaze over, because some staff glaze over." 
Staff interviewee four: "It's (promotion) one of those really tricky things... It's almost something that I feel like if just we did it, it still wouldn't make enough of an impact. Whether it's all library's that got together and did this massive campaign. Or whether the database people themselves did some."

Traditional marketing in the library's physical space should not be ignored, as some customers are still informed by it.

Customer one: "I always come in have a look at the noticeboard, the library displays and events that are coming up this week."

During interviews, the use of social networking to promote the EPIC databases was raised. All staff interviewees reacted positively and it turned out that this had not been done before.

Staff interviewee one: "We do actually use Facebook and Twitter. We do use them predominantly for marketing... Whenever there's an event or something we would always put it up on Facebook."

Staff interviewee four: "I think that would be a great idea...we've promoted things like e-books, but I don't recall the databases."

Two staff interviewees opined on the benefits of using social networking to promote the EPIC databases.

Staff interviewee three: "I think periodically just doing a post on any of those social media sites we use would be beneficial... People have to make a concerted effort at the moment to go into the library website and even possibly know that the EPIC databases are in our (internet resources), which people don't know."

Staff interviewee four: "The good thing about using social media would be you are targeting people who are online at home. So you're targeting people who are more likely to use the databases. But who our main Facebook users 
are is usually parents I would say, or older people. We haven't got the younger generation at all."

\subsubsection{Market segments}

Is the library targeting market segments to promote the EPIC databases?

All staff interviewees replied that the library is not targeting market segments, but were able to think of segments that could be targeted, including students, researchers, the elderly, local businesses and young parents.

Staff interviewee one: "I would say the majority of people who use them (EPIC databases) are students and they would range from secondary school students to tertiary."

Staff interviewee two: "We've got about 15 Schools: three of them are high schools, two are intermediates, the rest primary schools, Te Kohanga Reo, the play centres... the whole education sector here, not just for the kids, for their parents for the teachers. They'll be doing ongoing study I'm sure. That's a huge market that we do, we do need to capture and reach out to."

Staff interviewee three: "(With children we use)... the Literature Resource Centre, Biography in Context, sometimes the New Zealand Reference Centre... We use the Literature Resource Centre a lot for years eleven, twelve and thirteen English."

Staff interviewee three: "I think there could be a way that we could tailor each of these databases to a different demographic in our community rather than just EPIC databases as a whole."

Staff interviewee four: "Students obviously, because we do get students coming in here..." 
Staff interviewee one labelled researchers and people continuing their education after formal school systems as a segment. Staff interviewee three explained that genealogy enthusiasts are a group that could be targeted in the promotion of the Ancestry Library Edition database. Another staff interviewee corroborated this:

Staff interviewee four: “...there are a lot of people who use that (Ancestry). We've got a couple of groups who meet about looking at family history. And I know they do promote it amongst themselves and help each other."

One staff interviewee showed how they considered the elderly a market segment to be targeted.

Staff interviewee three: "I think the Health and Wellness Centre. They (the elderly) could really benefit from using that."

Just one staff interviewee highlighted local businesses as a potential and as yet unreached market segment.

Staff interviewee two: "There are so many little local businesses out here that we could be promoting that to. Loads of agencies that help in the community. We talk at them, we talk with them, we put on all manner of evenings but at no time are we promoting those databases."

The same staff interviewee had noticed a trend in Twitter conversations between staff and young parents.

Staff interviewee two: "There are young mums out there who are desperate for advice... We should be researching that... we could Tweet them and say 'Hey, try this database.'” 


\subsection{Product}

\subsubsection{Popularity}

Are the databases well used by library customers?

This question elicited a majority of negative answers. Staff interviewees two, three and four stated that they thought the databases are not well used. Two staff interviewees linked this to a lack of awareness.

Staff interviewee three: "They (customers) don't know what EPIC is."

Staff interviewee four: "No, I think they could be better used... Because they (customers) just don't know about them."

Staff interviewee one had a different opinion.

Staff interviewee one: "Yes I think they are, when I look at the statistics that I have seen."

The database usage statistics were seen to be vital to subscription decisions. However, statistics presented their own problem.

Staff interviewee one: "We get statistics from EPIC and I find them really hard to use because they don't break it down to individual databases. They break it down to journals within a database... I've gotta get to the bottom of the stats thing. So that we can make an educated decision about whether we continue with them (subscription to individual databases) or not." 


\subsubsection{Ease of use}

Are the EPIC databases intuitive to use?

All staff interviewees found the majority of EPIC databases intuitive to use. One staff interviewee did note troubles they had with Ancestry Library Edition.

Staff interviewee four: “This is just probably because I don't use it enough, but Ancestry... Sometimes you'll put in a search for a person and a date range and it seems to bring everything else up... I'm not the only one, because I called in other staff and they couldn't figure it out either."

Customer one: "I find the PressDisplay and the Australia New Zealand Reference Centre quite easy to use, quite straightforward."

Interviewees gave their opinions on how customers might experience using the databases.

Staff interviewee one: “...people don't always choose the right terminology to search under and then they don't find what they're looking for."

Staff interviewee two: "Can see that for others they may not be (intuitive)."

Staff interviewee three: "A lot of people just don't know what that is (Boolean Operators)."

Customer one: "I have seen people who need help. So I gather that they are not familiar with the databases."

Several good ideas for helping customers emerged.

Staff interviewee two: “...online tutorials could be a real fun way of kids and adults learning... Why haven't we got one (TV information loop) that's totally dedicated to everything that is e-resources?" 
Customer one: "It would be good to have guidelines somewhere near the computers that the public can assess and know how to use them without any librarians."

\subsubsection{Priority of EPIC databases}

What priority do the EPIC databases have at the library?

This question revealed that two staff interviewees two and three considered the EPIC databases to have low priority at the library right now.

Staff interviewee two: "Sadly, they're not valued here... They're a huge priority to me... But, why would we invest that money and not let people know?"

One staff interviewee spoke on the value EPIC as an organisation has to libraries in New Zealand.

Staff interviewee one: "EPIC making it affordable for libraries has made a big difference... This has brought to the everyday libraries, small libraries, school libraries the ability to have access to those (databases) that our patrons wouldn't have had in the past."

\subsubsection{Other library priorities}

What has priority at the library?

Staff interviewees categorised library staff, community outreach, library programs and ebooks as being important. Staff interviewee two stressed the importance of the library's staff, their skill and commitment to the library framework.

Three staff interviewees saw that community outreach and library programs had become a high priority for the library, with negative impacts in other areas. 
Staff interviewee three: "There is a general push from higher up to be increasing our presence in the community... our web content is going 'by the by' in my opinion."

Staff interviewee two: "In general the clientele that we are really talking to now and thinking that we're gonna change the world with have become a priority in our promotions. So things like hot seats, budgeting advice, finding jobs. Yes, it's important, but really, to me and I'll put my political hat on here. There are government agencies that should be doing that and aren't."

Staff interviewee four: "We do a lot around employment. We run three different programs for employment and we promote those a lot because there's a big need in the community for those."

Three staff interviewees reported programs as having high priority and promotion at the library. These included things like arts and crafts, a music club and after school programs. Two staff noted the growing importance of e-books and their consequent promotion through social media.

\subsubsection{Relevance}

What relevance do the EPIC databases have to library customers?

Two staff and one customer believed that the EPIC databases are relevant to library customers. Two staff mentioned the elderly and individual students as people who would find particular relevance in the EPIC databases. Another interviewee showed how the EPIC databases were an efficient way of finding specific information:

Staff interviewee four: “...you get questions where it's very specific, they know exactly what they want and you can't find it in a book because it might be a paragraph in the whole book and it's impossible to find that one paragraph. And they don't want to sit there and read the whole book to find that one paragraph. So to be able to use the databases you can find that article..." 
The customer thought those interested in the arts, history and genealogy would find the EPIC databases relevant. Two staff interviewees held different views on relevance. One staff interviewee noted that some of the EPIC databases are almost too academic.

Staff interviewee one: "The majority of our patrons actually do just want to look for books. They didn't want to know that we had a hundred journal articles on Harry Potter..."

Staff interviewee two: "Maybe the sites that we're buying from EPIC are maybe not reflecting the needs."

The future decisions on EPIC subscription will be influenced by costs and an assessment of needs and relevance:

Staff interviewee one: "We are not going to subscribe to those that are too high of an academic level... we want the ones that are of more interest to the general population... The thinking behind this is that if you're a tertiary student you should have access through your own university library or tertiary institute library... there's only so many dollars and we have to be very wise in how we spend it."

\subsubsection{Competition}

What competition is there to the library's EPIC databases and what can be learned from this competition?

Two staff interviewees saw Google as competition and interviewee two stated that it was a point of first call for staff. Staff interviewee three initially answered that they did not know what the competition to the EPIC databases was, but agreed with Google and Wikipedia as competition when they were suggested. One staff interviewee did not mention Google or Wikipedia directly as competition, though they elaborated: 
Staff interviewee one: “...the students who come in are directed by their teachers not to use Wikipedia. So they are coming in looking for something that's more authoritative."

When asked what might be learned from competitors, three staff answers dealt with either Google's simplicity or speed of use. A staff interviewee outlined one of Google's weaknesses but also a way that the EPIC databases could be improved.

Staff interviewee three: "Using Google it will bring up impure information or something that's not accurate. If we could use that ease of use, just type it in with no search terms, find my exact phrase on the EPIC databases and bringing up that accurate information for them would just be amazing."

Staff interviewee four: "For a general person coming to it (Google) the first time they literally just type the question in and put a question mark at the end and Google can handle it. I don't think our databases could."

Upon asking one staff interviewee if they thought customers preferred to use Google or Wikipedia over the EPIC databases, they replied:

Staff interviewee three: "I think yes... For example the Google homepage is a one click. You can type in exactly what's in your head without having to click all search terms etc. You can just put it in and it will come up straight away. It's that real ease of use."

One staff interviewee explained how the EPIC databases could do with a marketing campaign and rebranding.

Staff interviewee two: "It needs to get maybe a catch-phrase... Everybody knows about Google... EPIC is a fantastic word, but what does it mean?"

Three staff interviewees said that in their experience customers hadn't asked for other resources. Staff interviewee one stated that people were asking for more e-books and links to government websites. The customer interviewee had some requests: 
Customer one: "Yes, the other ones I would like to see are entertainment sections, whether it is TV, movies or concerts around this region and the country."

\subsection{Place and price}

\subsubsection{Evaluating accessibility}

How accessible are the EPIC databases?

Two staff interviewees said that the EPIC databases had become more accessible due to the new library management and discovery service, Kōtui.

Staff interviewee one: “...I know from working here at a time before we had the discovery service, it seriously was really hard to do research... So sometimes it would take ages to hunt through each heading to find which database to look in... the ability now to be able to search across all of them at once, that just has to make them far more successful."

Staff interviewee four: "I think through the Kōtui catalogue they are easy (to access) in that it does the search for you, you don't have to pick a database to go into. It searches them all for you, which does definitely make it more user friendly."

Staff interviewee three was not of the same opinion about Kōtui:

Staff interviewee three: 'I just think there's not enough push... when you're looking at it through the library catalogue there's still just a tiny, tiny little link down the bottom saying (internet resources). It's just not clear enough to the general public who are using the catalogue that those resources are there for them."

Problems with accessing the EPIC databases were raised, specifically their hidden nature. 
Staff interviewee two: "All our EPIC databases are hidden in layers on our website and in our catalogue, under a tab called (internet resources). Now I love that... I think it's quite trendy and to the point."

Another staff interviewee thought differently:

Staff interviewee three: "As far as where they are, they get absolutely bypassed. I think the whole concept of (internet resources) is really obtuse on our website."

The customer's opinion backed up this assertion:

Customer one: "Not many people know about this (internet resources link)."

Staff interviewee four thought that an awareness problem was affecting customer access to the databases. The customer outlined two problems they have had with accessing the EPIC databases, one which occurred after Kōtui was launched.

Customer one: “...when I couldn't find the site. It seemed to have moved somewhere."

The second had to do with using the databases on library computers.

Customer one: "Only there are times when there seems to be a slowdown in the network. Then it takes a bit." 


\subsubsection{Improving accessibility}

Three staff interviewees suggested methods of improving visibility to increase accessibility.

Staff interviewee two: "I would like to see something that said EPIC databases right on the front page of our catalogue, right on the front page of our website."

Staff interviewee three: "By making it a lot more visible on the catalogue and on our webpage.... Our EPIC databases are lumped in with handy websites. I would like them to have their own button... saying what they actually are."

Staff interviewee four: "Well, it is easy (to access) through the catalogue but it's not obvious. It's not staring you in the face as the first thing you see. You have to know... So it's that awareness kind of thing. I don't know if we can make this big thing flash up on the screen going 'Have you tried our databases?" 


\section{Discussion and analysis}

\subsection{Current database promotion}

The most important finding of this study is that according to interviewees the library is not promoting its EPIC databases, indicating a problem crucial to the study's objective. Recognising marketing problems and their effects could encourage problem solving efforts. Two staff interviewees noted that customers are often surprised to hear of the EPIC databases and the customer's opinion reinforced the idea that the databases are not well known or promoted. This may indicate a connection between customer awareness and lack of promotion.

Three staff interviewees detailed now defunct electronic and physical means of EPIC database promotion. It is unclear why these efforts were discontinued, though one staff interviewee linked this to the introduction of a new library management and discovery service, Kōtui, which allows simultaneous queries to all EPIC databases. Another possible reason is a shift in library priorities, explored under section 5.3 Increasing priority. One staff interviewee linked accessibility issues to the need for promoting EPIC databases in the past. If true, are the databases easier to access now? This is considered under section 5.7 Accessibility.

Numerous marketing initiatives for improving EPIC database promotion arose during this study, including the renewal of past promotion efforts, community engagement, the use of social networking and the design of a New Zealand wide EPIC promotion initiative.

Staff interviewee two suggested that the library's monthly newsletter reinstate its advertisement of EPIC databases. However, this would only target customers who read it. Another idea of looping information about the EPIC databases on the library's TVs would employ existing technology. The library's small physical space was identified as a limitation, however a small area could host a series of eye-catching displays to inform customers of EPIC databases and their uses. This physical promotion would complement the advertisements in the library newsletters. Staff also suggested an EPIC database banner for the library website to pique customer curiosity at the point of access to the library's website. 
According to staff, community engagement could take the form of EPIC database usage training offered by librarians for customers. However, this would rely on customers being aware of the databases and in need of the information they provide. One staff interviewee put this starkly:

Staff interviewee two: "We can come up with all the sessions we like, if the kids don't want them they're not gonna engage."

This could be applied to all customers and is why identifying market segments and targeting promotion (covered in section 5.2) is important.

Outreach could also be achieved through introducing new customers to the EPIC databases on point of registration. This was suggested by staff and could be introduced as library policy. Customer outreach is explored in more detail section 5.3.

The use of social networking to promote EPIC databases saw support from staff in this study. This might involve periodic promotion of individual databases and could fit into the existing social media plan. However, this only targets current users of library social media and those who have internet access. Also, staff pointed out that it is predominantly the older generation who follow the library's social media; younger library customers may not be reached effectively in this way.

The final and most complicated method of improving database promotion suggested by staff consisted of a New Zealand wide initiative. This might involve LIANZA (Library and Information Association of New Zealand Aotearoa), EPIC and the National Library collaborating to assess the marketing of the EPIC databases throughout New Zealand. This could mean countrywide studies seeking to prove a need for action, establish areas of weakness and develop a plan with measurable goals.

The solutions offered above, with the exception of the New Zealand wide initiative, are all affordable and easily adopted provided the EPIC databases are given high enough priority. Reference to EPIC database usage statistics before and after could help measure the success of adopted solutions. 
This study's interviewees all asserted that the library's EPIC databases are not currently being promoted. If promotion has any effect on the use of a product then at this library inadequate promotion may be contributing to the underuse of the EPIC databases. However, the relevance of the product itself, accessibility and usability may also be factors contributing to low EPIC database use by customers.

\subsection{Market segments and product relevance}

According to staff interviewees, the library is not targeting market segments to promote its EPIC databases. This is not surprising as the databases are not being promoted. Staff interviewees named segments they believed would benefit from the EPIC databases: students, non-student researchers, the elderly, young parents and local businesses. Additionally, future changes to EPIC subscription methods may see attention turn towards marketing EPIC databases at this library.

All staff interviewees identified students as a group that would benefit from the EPIC databases, especially due to the large and varied education sector in the library's area. Nonstudent researchers could find the EPIC databases relevant and the elderly could benefit from the use of the Health and Wellness Centre database.

One staff interviewee said the library is in touch with local agencies but is not promoting EPIC databases to them. Local businesses are a potential market because they could benefit from Business Insights: Global, RDS Business Suite and OneFile (General, Master and Academic). These databases might help local businesses keep abreast of developments in their environments.

Interestingly, one staff interviewee identified discussions staff were having with customers through Twitter. Young parents were asking for advice on raising children and this staff interviewee believed that the library should be investigating if their information needs could be met through the EPIC databases. Health and Wellness Resource Centre might be of use for this market segment. 
Before any market segments are finalised, it would be prudent to perform market research to verify their existence and size. As pointed out by one staff interviewee:

Staff interviewee two: "Don't assume you know your community."

Kavulya (2004, p.118) supported this, stating marketing involved identifying needs, then meeting them. Relevant EPIC databases might exist that would benefit newly identified market segments.

Staff interviewee two: "Let's have a look at community needs (through social media) and go back to EPIC and say that's what we need."

This leads to the upcoming changes to EPIC database subscription and the consequent purchasing decisions. These changes present an opportunity and reason for market research and targeted marketing at this library. One staff interviewee recognised that this change could see increased attention given to the EPIC databases, their promotion and cost.

Staff interviewee one: "Because they're so expensive that if you have to pay for them individually I can see that you will only choose ones that you feel are going to be very well used. And then you might be inclined to want to market them more. Just because you're more aware of the fact that you're actually paying for this individual database and you want to make sure that you're getting value for money. And if it doesn't perform over this year, then in the next financial year we might decide to drop it."

Identifying market segments through market research would be a good first step towards more effective marketing of the EPIC databases. However, this would require resources and money. It is possible that the upcoming changes to EPIC subscription will bump EPIC up the priority list at the library.

\subsection{Increasing priority}

This study revealed that staff interviewees hold different opinions on EPIC database priority. Community outreach programs were identified as having the highest priority, with e-books 
receiving notable mention. One staff interviewee stated that library staff are the most important resource and their education had high priority.

Two staff interviewees believed the low priority of the EPIC databases was unfortunate because they are a reliable and accurate source of information. Additionally, interviewees pointed out the value and cost of the databases to the library.

Staff interviewee one: "They do cost us a lot of money. So we wouldn't subscribe to them unless we saw their value."

Staff interviewee three: "(Important to)...make a big push on the promotion for it. Any promotion. Because it's such a valuable resource. I think also educating people. Promoting it through the context of that accurate information as opposed to what they're looking up and the faff they may find online. Otherwise it's a complete waste of money, which it is at the moment in my opinion."

One staff interviewee also stressed that EPIC as a consortium has been of great value to small libraries that otherwise would be unable to afford access to databases. Lack of EPIC database promotion as shown by staff interviewees may indicate their low priority. If the EPIC databases have low priority, what has high priority at the library and why?

Staff interviewees explained how community outreach had become a priority at the library. This involved budgeting and employment advice, legal information, website design, instruction in the use of government websites and more. A subject professional visits the library to field questions and give advice. One staff interviewee explained how the local council was influencing library priorities by drawing attention away from other initiatives. This position was backed up by another staff interviewee who said that web content was being negatively affected.

Staff interviewee two: "I worry that we are losing sight of core services. Absolutely we have to engage with our community, but I believe we do that by the very nature of opening our doors at 10 o'clock every morning... we are becoming very much a social band aid." 
Staff interviewee three: "There is a general push from higher up to be increasing our presence in the community through these events that we host. Any of our web content is going 'by the by' in my opinion."

Staff interviewee two saw community outreach as important but thought that some instances of outreach were outside the library's immediate purview. They felt that the library is taking on work other government organisations should be doing. It would be interesting to know if the EPIC databases could be used to facilitate customer outreach in these areas. If this is the case, there would be strong reasons for subscribing to these databases and advocating them to local government agencies and support groups. These agencies and groups could promote the EPIC databases to their clients and point them to the library for support.

A benefit of this study was speaking with staff members, increasing attention to the EPIC databases and encouraging critical thought about EPIC's place in the library. Though the EPIC databases currently have low priority, they could be used flexibly to support the current focus on community engagement.

\subsection{Adapting to competition}

This study revealed that Google and Wikipedia's simplicity was something library staff would like to harness for their catalogue. A majority of staff agreed that Google was a source of competition to the EPIC databases and the issue of EPIC database branding was also raised. Staff interviewees had not seen a demand from customers for other types of resources apart from e-books, though the customer interviewee expressed a desire for a wider range of entertainment resources on the library website.

One staff interviewee believed that some staff turn to Google before the EPIC databases. In a similar vein, another staff interviewee noted that some staff would direct customer questions to them. Stronger EPIC database training would help increase staff familiarity and knowledge of what the resources can be used for.

Staff interviewee one: "If it's too hard to get results then people tend to want to give up." 
The ubiquity of Google meant that all staff interviewees could draw from it ways to improve the library's EPIC databases. At the forefront of opinion was its simplicity and speed. Staff interviewee three made the salient point that the natural formulation and execution of searches possible through Google could not be handled by the EPIC databases. Other staff thought that this method of direct questioning was preferable for customers. However, this was tempered by the acknowledgement that Google results are often unreliable. Has Google cast customer searching habits in a mould ill-suited to the current permutation of EPIC database retrieval systems? This question was not explored by this study.

A staff interviewee had the idea of rebranding the EPIC databases, thinking they are "...almost too academic" and in need of a catch-phrase. This could work in tandem with market research. Instead of rebranding the EPIC databases holistically, individual databases relevant to market segments could be branded to speak to their intended audience.

How can the EPIC databases successfully co-exist with Google and Wikipedia? As mentioned by staff interviewee three, stressing the accuracy and reliability of EPIC databases in comparison to Google and Wikipedia is a start. Staff are available to help customers with their information needs using EPIC and this should be promoted. A long shot might be to gather support from other libraries in New Zealand to petition for EPIC database providers to improve usability and accessibility.

Usability and accessibility may be influencing decision making when staff and customers are considering Google, Wikipedia and the EPIC databases for their information needs. Kaur (2009) believed librarians out of touch with user needs resulted in poor marketing of library resources causing users to have no reason to stop relying on internet search engines. This study did not show that staff were out of touch, but does reinforce the need for marketing. The next section considers data collected on both usability and accessibility in the hope of establishing ways of increasing EPIC database use.

\subsection{EPIC database usage}

This section centres on a discussion of EPIC database usage and statistics. Concluding whether or not the databases are well used from the data gathered in this study was difficult 
because data came in the form of a small number of staff opinions and was anecdotal in nature.

According to three staff interviewees, the EPIC databases are not well used. Two of these interviewees tied this to lack of awareness, which is not surprising considering the library is not promoting the EPIC databases. The staff interviewee who thought they were well used cited usage statistics they had seen, but couldn't be sure of their accuracy because they are hard to interpret. Statistics are broken down to individual journals within each parent database, making them hard to analyse. The detail is at too low of a level to assess overall usage in a simple way. This depth of detail might be of more help to a database provider deciding which journals to offer. But as staff interviewee one explained, they “...just want to know how many times that (Opposing Viewpoints) gets used in a week or in a month." Additionally, this staff interviewee felt that statistics could play an important part in the inevitable subscription decisions in the future.

From this discussion it follows that a better understanding of the EPIC database usage statistics is needed at this library, with the establishment of measurable usage goals to aid future database subscription decisions. To conclude on EPIC database usage with accuracy, a detailed look at statistics over time in reference to usage goals would be necessary. This could be achieved through a study similar to McClure et al.'s (2012, p. 369), which focused on usage statistics to increase marketing efficiency.

\subsection{Intuitiveness of use}

This study showed that staff interviewees found the majority of their library's EPIC databases intuitive to use. However, it must be noted that these staff occupied middle to upper management positions. No library assistants were interviewed and they could have provided a better sketch of staff proficiency with EPIC databases.

This study also gathered staff opinion on problems customers have during EPIC database use, including the use of unsuitable terminology and unfamiliarity with Boolean search operators. Arguably, these are not problems often experienced when using Google. The customer interviewee found the databases they use straightforward to operate, but noted that other customers seemed to struggle. The Ancestry Library Edition database was seen by one staff 
interviewee as being occasionally difficult. This is important because Ancestry was highlighted as a particularly well-used database by two staff interviewees. Staff knowledge of the EPIC databases was pointed out as a problem by two staff interviewees. For these reasons, further staff and customer training initiatives should be considered. This would help interested customers and bolster staff confidence when aiding customers in the use of Ancestry.

Customer training could be direct, or indirect. Staff interviewee two suggested online tutorials and the use of the library's TVs to educate on the use of EPIC databases. The customer thought guidelines on EPIC database use should be adjacent to library computers. The guidelines might target popular databases as uncovered by market research or a customer survey.

It was difficult to measure the intuitiveness of using the EPIC databases through this study because its main focus was improving promotion. A different study could address the strengths and weaknesses of database intuitiveness through a comprehensive study of all EPIC databases from their varying providers. The call for visibility was found in Kaba's (2011, p.60) study, along with general information, consultation, online services and resources. All which would improve website usability and could be applied to marketing the EPIC databases.

\subsection{Accessibility}

Staff interviewees were divided on the subject of EPIC database accessibility. Two staff thought the new library management and discovery service, Kōtui, had a positive effect on EPIC database use. Other staff believed the EPIC databases were hidden and low customer awareness was negatively affecting access.

Kōtui allows customers to toggle between database or book results in catalogue searches. Since Kōtui allows catalogue searches to query all EPIC databases there is no need to find a specific database before searching. However, there still remains a problem of awareness and promotion. Do customers know they can search for complex information not found in books through toggling on the EPIC database? One staff interviewee believed they do not. The 
library should not rely purely on Kōtui to solve problems of access; it should be supplemented by promotion of the EPIC databases and Kōtui's capabilities.

There were conflicting staff opinions about the internet resources link on the library's home page. Staff interviewee two thought it fashionable and self-explanatory; staff interviewee four thought it obtuse. The latter's opinion is supported by the customer who believed that customers were not cognizant of the link. This provides limited evidence supporting the position that the EPIC databases have accessibility problems. If customers are unaware of the link and what it contains then they are unlikely to use it.

Lastly, the customer interviewee mentioned experiencing network slowdowns when accessing EPIC databases during peak hours at the library. This was not mentioned by any staff interviewees. Asking more customers about this could identify if it is a recurring problem that needs to be addressed.

This study's interviews provoked a discussion on improving access to the EPIC databases. Three staff interviewees suggested raising the visibility of the EPIC databases on the library home page to increase awareness of the resources. This links back to better promotion; customers need to know what the EPIC databases can do for them and how to access them. Staff interviewee three suggested that the EPIC databases get a dedicated, eye-catching link to separate them from other resources.

Though Kōtui may improve access to the EPIC databases, it should be bolstered with promotion to ensure customers know the capabilities of Kōtui and the EPIC databases. A call for database usability research may prove beneficial to identification of troubles that staff and customers experience with specific EPIC databases. These troubles could be addressed through targeted training for both parties. 


\section{Conclusions and recommendations}

This study set out to improve the efficiency of EPIC database marketing at the target library. Through staff and customer interviews it was found that the library was not marketing its EPIC databases, though it had in the past. The library also had not targeted market segments to promote the databases, in the past or present. It is recommended that the library undertake market research to identify customer segments that would benefit from the library's EPIC databases. Focus could be given to the staff identified segments of students, non-student researchers and local businesses.

The EPIC databases would benefit from promotion to these market segments because marketing would successfully target groups that are known to require the EPIC databases. A renewal of old promotion efforts and establishment of new initiatives could improve customer awareness and increase EPIC database visibility. This could be achieved through:

- The use of Twitter and Facebook to promote EPIC databases

- The creation of physical EPIC database displays

- The use of library TVs to loop information on EPIC databases

- EPIC database section in monthly library newsletter

- Creating an eye-catching EPIC banner on the library's homepage.

The forthcoming changes to EPIC database subscription in 2014 provides justification for increasing market research to ensure subscriptions are kept to databases that are relevant to customers and that good monetary investments are made.

This study found a connection between inadequate promotion, low customer awareness and low usage of EPIC databases. The majority of interviewed staff believed the EPIC databases were not well used. However, due to a small sample size and limited customer data, the study was unable to definitively prove this. Analysis of usage statistics and comparisons with similarly sized libraries would help to quantify EPIC database usage. It is likely that not promoting the EPIC databases has resulted in less customer usage due to low awareness. 
The study also found that staff opinion on EPIC database accessibility was divided. While Kōtui's retrieval capabilities will help to address the concerns of how hidden the EPIC databases are, if customers do not know about these resources, they cannot turn to them for their information needs. The internet resources link as a point of access to the EPIC databases was also contentious. Staff had recommendations worth exploring; making the link prominent and clearer in its meaning and separating the EPIC databases from general electronic resource links.

It was found that the majority of EPIC databases were intuitive for interviewed staff to use. The study revealed that some staff interviewees thought staff could be better trained in the use of the EPIC databases. Library assistant staff were not interviewed during this study and their opinion could have added depth to results. Also it was believed that customers could struggle to use the databases. Further staff training is recommended so that educating on and using the EPIC databases becomes second nature. Community engagement initiatives could be modified to include training in database use for customers.

Another finding was that the EPIC databases had low priority compared with customer outreach. Low priority could explain the lack of promotion. If possible, utilising the EPIC databases to aid in customer outreach would be a prudent idea. It might be possible to use the databases to find information for customers on employment, budgeting advice and legal information. The upcoming changes to EPIC database subscription provides a good reason to increase their priority.

\subsection{Future research implications}

- Due to the forthcoming changes to EPIC database subscription, a re-evaluation of marketing success in a year's time is recommended. This might be accomplished through a detailed consideration of usage statistics and a customer opinion survey.

- Research evaluating the usability of EPIC databases in connection with the possible effect Google has had on customer searching habits. This could identify if customers struggle to use the EPIC databases because they are used to Google's simplicity. The research question could be a variation of: 'Can the EPIC databases usability be improved to compete with sites like Google and Wikipedia?' 
- This study's methodology could be replicated in other public, school and special libraries to investigate EPIC database marketing issues and encourage new solutions. Future studies could benefit from the results of this study.

- Broader research into EPIC database marketing throughout New Zealand could provide the justification for collaboration with other libraries in NZ. If a general problem with marketing is found, this could encourage EPIC, LIANZA and the National Library to establish a plan for improving EPIC database marketing throughout New Zealand.

- Research into network slowdowns at the study library to find out to what extent the slowdowns inconvenience customers.

- An examination of the effectiveness of marketing resources provided through EPIC's website (n.d., EPIC website: Marketing Resources). 


\section{Bibliography}

Ashcroft, L. (2002). Issues in developing, managing and marketing electronic journals collections. Collection Building, (21)4, 147-154.

Brannon, S. (2007). A successful promotional campaign. The Serials Librarian, (53)3, 41-55.

Brower, S. M. (2004). Academic health science library website navigation: An analysis of forty-one websites and their navigation tools. Journal of the Medical Library Association, 92(4), 412-420.

Cherrie, C. \& Rigby, F. (2007). The EPIC LIANZA training initiative - Transforming online skills training. Paper presented at the LIANZA conference, 1 September 2007. Retrieved February 13, 2014, from http://www.lianza.org.nz/resources/conferenceproceedings/2007/epic-lianza-training-initiative-\%E2\%80\%93-transforming-online$\underline{\text { skills-t }}$

de Sáez, E. E. (2002). Market segmentation. In Marketing concepts for libraries and information services ( $2^{\text {nd }}$ ed., pp.115-135). London, England: Facet.

Dubicki, E. (2007). Basic marketing and promotion concepts. The Serials Librarian, 53(3), 515.

EPIC website: About EPIC. (2011). Retrieved February 13, 2014, from http://www.epic.org.nz/about-epic

EPIC website: Marketing Resources. (n.d.). Retrieved February 13, 2014, from http://www.epic.org.nz/marketing-resources

EPIC website: News, EPIC product offers, trials \& pricing proposals for 2014. Retrieved January 26, 2014, from http://epic.org.nz/node/276 
Flower, E. (2004). Competition, technology, and planning: preparing for tomorrow's library environment. Information Technology and Libraries, 23(2), 67-69.

Hart, J., Coleman, V. \& Yu, H. (2000). Marketing electronic resources and services: Surveying faculty as a first step. The Reference Librarian, 32(67-68), 41-55.

Kaba, A. (2011). Marketing information resources and services on the web: Current status of academic libraries in the United Arab Emirates. Information Development, 27(1), 5865.

Kaur, K. (2009). Marketing the academic library on the web. Library Management, 30(6/7), 454-468.

Kavulya, J. M. (2004). Marketing of library services: A case study of selected university libraries in Kenya. Library Management, 25(3), 118-126.

Kennedy, M. (2011). What are we really doing to market electronic resources? Library Management, 32(3), 144-158.

Kōtui website: About Kōtui. (n.d.). Retrieved January 26, 2014, from http://www.kotui.org.nz/about-kotui

Leedy, P. D. \& Ormrod, J.E. (2013). Practical research: Planning and design (10 ${ }^{\text {th }}$ ed.). Boston: Pearson.

Local Government New Zealand, \& Public Libraries of New Zealand. (2012). Public Libraries of New Zealand: A Strategic Framework 2012 to 2017.

MacDonald, K. I., vanDuinkerken, W., \& Stephens, J. (2008). It's all in the marketing: The impact of a virtual reference marketing campaign at Texas A\&M University. Reference \& User Services Quarterly,47(4), 375-385.

McClure, C. R., Mandel, L. H., \& Weissenberger, L. K. (2012). Designing a user and usage database to promote, market, and demonstrate the value of selected statewide 
databases: The Florida Electronic Library as an example. Library Management, 33(6), 365-373.

Reitz, J. M. (2014). Online Dictionary for Library and Information Science: discovery service. Retrieved January 26, 2014, from http://www.abcclio.com/ODLIS/odlis_D.aspx\#discoveryservice

Reitz, J. M. (2014). Online Dictionary for Library and Information Science: library management system (LMS). Retrieved January 26, 2014, from http://www.abcclio.com/ODLIS/odlis_L.aspx\#libms

Reitz, J. M. (2014). Online Dictionary for Library and Information Science: OPAC. Retrieved February 6, 2014, from http://www.abc-clio.com/ODLIS/odlis_o.aspx\#opac

Patton, M.Q. (2003). Qualitative evaluation. In Lewis-Beck, M.S, Bryman, A. \& Liao, T.F. The SAGE Encyclopedia of Social Science Research Methods. Retrieved February 13, 2014, from http://srmo.sagepub.com/view/the-sage-encyclopedia-of-social-scienceresearch-methods/n781.xml

Peshkin, A. (1993). The goodness of qualitative research. Educational Researcher, 22(2), 2329.

Rowley, J. (2012). Conducting research interviews. Management Research Review, 35(3), 260-271.

Schmidt, J. (2007). Promoting library services in a Google world. Library Management, 28(6/7), 337-346.

TrueCrypt (2014). Retrieved February 11, 2014, from www.truecrypt.org

Vasileiou, M. (2011). Marketing and promotion of e-books in academic libraries. Journal of Documentation, 67(4), 624-643. 


\section{Appendices}

\section{Appendix A: Library EPIC database subscription list}

The study library subscribed to 19 databases through EPIC.

- Academic OneFile

- Ancestry Library Edition

- Australia New Zealand Reference Centre

- Biography in Context

- Books \& Authors

- Business Insights: Global

- Contemporary Women's Issues

- Discovering Collection

- Global Issues in Context

- General OneFile

- Health \& Wellness Resource Centre

- Masterfile Premier

- Library PressDisplay

- Literature Resource Centre

- Opposing Viewpoints in Context

- Oxford Music Online

- RDS Business Suite

- Science in Context

- World History in Context. 


\title{
Appendix B: Participant consent and information forms
}

\section{Participant Consent Form}

\author{
Research Project Title: Evaluating EPIC Marketing
}

Researcher: Andrew Armour, School of Information Management, Victoria University of Wellington

I have been given and have understood an explanation of this research project. I have had an opportunity to ask questions and have them answered to my satisfaction.

I understand that I may withdraw myself (or any information I have provided) from this project, without having to give reasons, by e-mailing armourandr@myvuw.ac.nz before the 1st January 2014. I understand that if I withdraw from the project, any data I have provided will be destroyed.

I understand that any information I provide will be kept confidential to the researcher and their supervisor, kept in a locked digital folder, the published results will not use my name, and that no opinions will be attributed to me in any way that will identify me or the organisation I work for.

I understand that the data I provide will not be used for any other purpose or released to others.

I understand that because this interview is audio recorded, the recording and transcripts of the interviews will be erased within 2 years after the conclusion of the project. Furthermore, I will have an opportunity to check the transcripts of the interview.

Please indicate (by ticking the boxes below) which of the following apply:

I would like to receive a summary of the results of this research when it is completed. Email address.

I agree to this interview being audio recorded.

Signed:

Name of participant:

Date: 


\section{Participant Information Sheet}

Research Project Title: Evaluating EPIC Marketing

Researcher: Andrew Armour, School of Information Management, Victoria University of Wellington

As part of the completion of my Master of Information Studies, this study is designed to help public libraries improve their database marketing and increase database usage for a better return on investment. It also hopes to serve as a tool for assessing a database's product, price, place and promotion based on customer and staff opinion. This study's methodology and interviews could be replicated in other kinds of libraries to investigate marketing issues and to encourage new solutions. Victoria University of Wellington requires, and has granted, approval from the School's Human Ethics Committee.

Adult customers and library staff members will be invited to participate in this research. Participants will be asked to take part in an interview that could last up to 30 minutes. Permission will be asked to record the interview, and a transcript of the interview will be sent to participants for checking.

Participation is voluntary, and neither you nor your organisation will be identifiable in any written report produced as a result of this research, including possible publication in academic conferences and journals. All material collected will be kept confidential, stored in a locked digital folder and will be viewed only by myself and my supervisor, Dr Philip Calvert, Senior Lecturer, School of Information Management, Victoria University of Wellington. The research report will be submitted for marking to the School of Information Management, and subsequently deposited in the University Library. Should any participant wish to withdraw from the project, they may do so until the $1^{\text {st }}$ January 2014 , and the data collected up to that point will be destroyed. All data collected from participants will be destroyed within 2 years after the completion of the project.

If you have any questions or would like to receive further information about the project, please contact me at armourandr@myvuw.ac.nz or telephone 027-224-7000, or you may contact my supervisor Dr Philip Calvert, Senior Lecturer, School of Information Management, Victoria University of Wellington at philip.calvert@vuw.ac.nz or telephone 04-463-6629.

Andrew Armour 


\section{Appendix C: Guide interview questions}

\section{Staff interview questions}

1. How are the EPIC databases promoted currently? What do you think are the strengths and weaknesses of this promotion?

2. Is there anything you would like to see done to improve database promotion?

3. What do you think about using social networking to aid database promotion? Is it a good or bad idea and why?

4. Is the library targeting market segments to promote the EPIC databases? What are the segments and do you think they are being reached? (Might small local businesses be a potential market?)

5. What priority/importance do the library's EPIC databases currently have? What has high priority at the library right now?

6. Do you think the resources are easy to access? How so? How do you think access could be improved?

7. Do you think the resources are intuitive to use? How so?

8. When you're looking for information, do you use the EPIC databases? Why or why not? [It will be made clear that this question need not be answered if the participant appears to be uncomfortable with it.]

9. Do you think there are external resources that compete with EPIC's coverage? If so, what are they? Do you think anything can be learned from how they operate?

10. Do you think the databases are well used by your customers? Why or why not?

11. Do you think these databases are relevant to your customers' needs? Why or why not?

12. Have customers asked for other electronic resources? What kind of resources have been asked for?

13. Do you have any concerns or other comments regarding the EPIC databases? 


\section{Customer Interview Questions}

1. How did you first learn about the EPIC databases you use?

2. How well do you think the library is promoting its EPIC databases?

3. How would you like to see EPIC database promotion improved? [Perhaps for the databases you use.]

4. What sort of database promotional material from the library have you seen?

5. What do you think about using social networking to help promote the EPIC databases? Would you be interested in learning more about the EPIC databases through Facebook, Twitter, Flickr, Vimeo or YouTube/something else?

6. What kind of marketing do you find effective?

7. Are the EPIC databases a time effective way for you to find information? Why or why not?

8. Do you think the EPIC databases are easy to access? If yes, how so? If no, why not? How do you think access could be improved?

9. Do you think the EPIC databases are intuitive to use? If yes, how so? If no, why not? What would make them easier to use?

10. Did you ask for assistance when you started using the EPIC databases? If so, what did you think of the help you got?

11. Could you tell me which EPIC databases you use and why? [It will be made clear that this question need not be answered if the participant appears to be uncomfortable with it.]

12. From the list of databases I gave you, which are relevant to your information needs and which are not? Why?

13. Do you think these databases are relevant to other customers? What kind of customers and why?

14. Would you like to see other kinds of databases available through the library? If so, what sorts of subjects would you like to be covered?

15. Are there other sources of information you turn to in preference to the EPIC databases? If so, what are they and why do you prefer them?

16. Do you have any concerns or other comments regarding the EPIC databases? 
Andrew Armour

INFO 580 research project

Word count: 13,203 